\title{
Artificial substrata colonized by freshwater lichens
}

\author{
Christine KELLER
}

\begin{abstract}
Small clay cubes, fired at different temperatures and mounted with nylon touch and close fastener (Velcro ${ }^{\mathbb{R}}$ ) on acrylic glass plates, were used in an experimental design to study colonization of artificial substrata by lichens. The cubes were exposed in alpine streams for either 5-7 y at five different sites in the Swiss Alps: Flüelatal (three sites) and Brigels (Canton of Graubünden), and Eggerberg (Canton of Valais). Only a few cubes were lost, except at two sites, where complete plates were lost - due to the strong water current and, probably, trampling by cattle. After $3 \mathrm{y}$, freshwater lichens had grown at three sites. At the most elevated site, colonization was observed after $4 \mathrm{y}$; at one site no lichen growth was recorded. The first colonizers of the new substrata were the locally most common species. Freshwater lichens preferred the surfaces of clay cubes fired at lower temperature, whereas exposed pieces of local rocks were less frequently colonized. Improvements in the experimental design are suggested.
\end{abstract}

Key words: alpine streams, artificial substrata, colonization, freshwater lichens, outdoor method

\section{Introduction}

Alpine streams harbour a specific lichen flora that probably includes more than 50 species adapted to aquatic or amphibious habitats (e.g. 24 species in Keller \& Scheidegger 1994). Seasonal and short-term fluctuations of the water level, responsible for the ruderal character of the stream bed and for temporary submersion, and a wide amplitude of daily and seasonal temperatures, are the dominant ecological factors influencing the lichen vegetation. Lichen species growing under such climatic conditions presumably have rather low growth rates. However, most rocks in alpine streams are, with some exceptions, largely covered by lichens. It seems that these freshwater lichens have developed successful strategies to occupy these disturbed frequently fluctuating environments. Nevertheless, the colonization of substrata by lichens is still poorly understood, although studies have been published on the establishment of

C. Keller: Swiss Federal Institute for Forest, Snow and Landscape Research WSL, Zürcherstrasse 111, CH-8903 Birmensdorf, Switzerland. lichens on rocks (Kristinsson 1970a, $b$, 1974; Armstrong 1981), the recolonization of burned areas (e.g., Ahti 1977; Wolseley 1997), the colonization of tree bark and twigs (Degelius 1964; Jahns et al. 1979; Hilmo \& Såstad 2001) and the establishment and development of foliicolous lichens (Sanders \& Lücking 2002). Moreover, the lichen community of freshwater streams has not been investigated in this respect and appropriate methods have never been published.

This paper presents a method for the study of colonization of artificial substrata by freshwater lichens in natural habitats. Small substratum units periodically collected facilitate the observation of lichen establishment and growth both macroscopically and with dissecting and scanning electron microscopes. Fired clay cubes as artificial substrata for lichens have been used previously for laboratory (Jahns 1993) and outdoor culture experiments (Honegger 1993). In view of the harsh environmental conditions in alpine streams with seasonal freezing, temporary submersion and desiccation, and a time span of several years necessary to study colonization, it was necessary to 

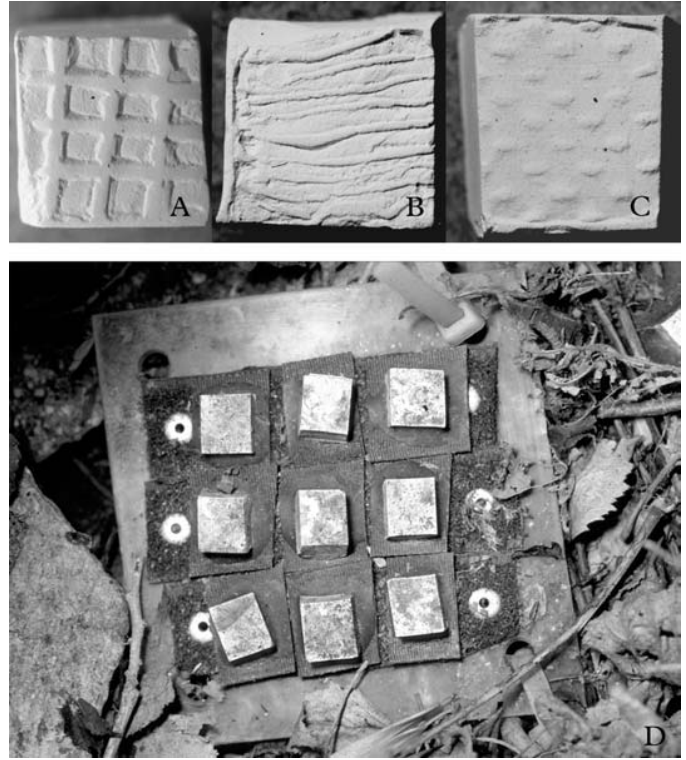

FIG. 1. Artificial substrata. A-C, clay cubes with different top surface structures $(c .1 \times 1 \times 0.5 \mathrm{~cm})$; D, acrylic glass plate with 9 cubes type 1280; exposed for three years at Eggerberg.

design a physically robust experimental system. At more or less regular intervals, the growth of organisms on the exposed artificial and rock substrata was recorded. The results document the successful application of the method, and include observations of colonizing freshwater lichens and of their preferences concerning hardness and surface structure of the substratum.

\section{Material and Methods}

The method used in this study was adapted from those previously described by Schuster et al. (1985), Jahns (1993) and Honegger (1993). Chalkfree clay cubes (c. $1 \times 1 \times 0.5 \mathrm{~cm}$ ) with different surface structures on the top face and with smooth sides (Fig. 1A-C) were used as artificial substrata. Half of the cubes were fired at $900^{\circ} \mathrm{C}$ (type 900 , softer surface; Mohs hardness $4 \cdot 5$ ), the other half at $1280^{\circ} \mathrm{C}$ (type 1280 , hard surface; hardness $7 \cdot 5$ ). The bottom of each cube was glued to a part of a nylon touch and close fastener (Velcro ${ }^{\circledR}$, Fastech Europe AG, CH-Seltisberg) using Araldit ${ }^{\circledR}$ (Vantico AG, CH-Basel). The other half of the fastener was glued and fixed with rivets onto acrylic glass plates (Fig. 1D). Series of 9 and 16 cubes were mounted on plates of $9 \times 9 \mathrm{~cm}$ and $11 \times 11 \mathrm{~cm}$, respectively. All cubes on a plate were of the same type; on the larger plates cubes with four different top surface

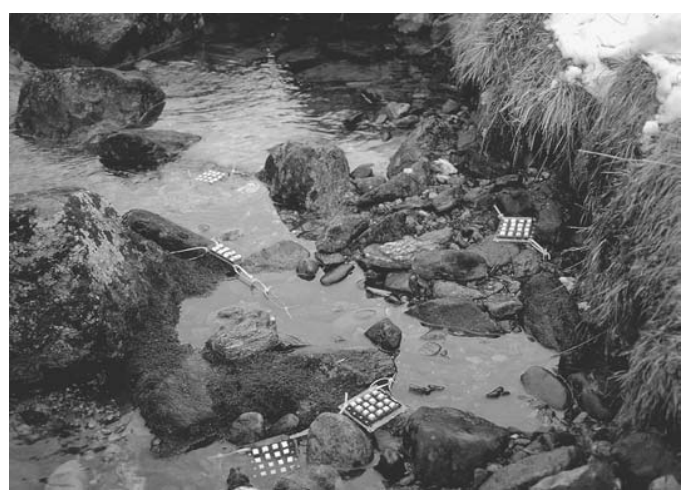

FIG. 2. The experimental site at Flüelatal-Säss with exposed plates.

structures were combined. The plates were anchored with tent pegs and cable binders in the stream bed (Fig. 2 ); both firing types and the different top surfaces were placed at the sites. Three of the five selected locations were relatively undisturbed alpine streams in Switzerland, in the area of earlier studies (Flüelatal, 1980$2240 \mathrm{~m}$ a.s.1.; Keller \& Scheidegger 1994); one of the sites was chosen with almost permanent submersion of the plates. The fourth location was a rather disturbed subalpine stream (Brigels, $1400 \mathrm{~m}$; pasture) and the fifth an artificial watercourse in the montane zone (Eggerberg, $870 \mathrm{~m}$ ). Local rocks (phyllite) at the Flüelatal-Säss site were brushed, sterilized, broken into pieces of roughly $1 \times 1 \times 1 \mathrm{~cm}$ and similarly fixed on plates of $9 \times 9 \mathrm{~cm}$. The rock fragments serving as controls were exposed at four locations. The sites were visited every year from 1991 to 1996; cubes with traces of lichen growth (hand lens, $\times 10$ ) were collected. At two locations the experiment ran until 1998.

\section{Results}

\section{Experimental design}

The standardized size of the clay cubes facilitates preparation for and fits well into the SEM-chamber. Also, the cubes are of uniform composition and, after firing, free of contaminating organisms. During the first five years of the study, only $45(7 \%)$ of all clay and rock cubes were lost. Four additional clay cubes (Eggerberg) and a second plate of controls (Brigels) were lost in the subsequent two years. A number of cubes were found detached in the first months of the experiment and were fixed on the plates again for the rest of the investigation period. The detached cubes showed 
no obvious differences when compared (hand lens) with cubes on the plates. The glue adhered better to the touch and close strips than to the clay cubes; after five years, some cubes had fallen off the plates leaving the glue on the strips, namely at FlüelatalSchäferen. Several cable binders were partly or almost worn through after three years and had to be replaced.

\section{Colonization, lichen growth and substratum preferences}

Four months after the start of the experiment many cubes were more or less covered by a biofilm including algae, diatoms, fungal hyphae, spores and bacteria (Fig. 3A). However, the first colonization by lichens was observed at three locations after three years (Table 1), and at Flüelatal-Karlimatten after four years. The artificial substrata at the Flüelatal-Säss site (Fig. 2) were not colonized within the five-year period. Lichens were detected with thallus sizes of $0 \cdot 5-1 \mathrm{~mm}$ diameter. Their paraplectenchymatous structure suggested that they were Verrucariaceae (Fig. 3E), but the development of perithecia was not observed at the alpine sites. The largest thallus measured after three years was $c .0 .5 \mathrm{~cm}^{2}$, with mature perithecia and ascospores (Verrucaria funckii (Spreng.) Zahlbr; Fig. 3B \& C; Brigels). The maximum lichen cover on a cube reached almost $2 \mathrm{~cm}^{2}$ after seven years and consisted of several confluent thalli. Staurothele sp. (Fig. 3D) covered $3 \mathrm{~mm}^{2}$ after three years at Flüelatal-Schäferen; it measured $7 \mathrm{~mm}^{2}$ after five years. The largest thallus at Eggerberg (Verrucaria hydrela Ach.) was slightly smaller after three years.

The first colonizers of the artificial substrata were among the most common lichen species at each respective site. Lichen growth was observed on the top and the vertical surfaces of the cubes, but also on the glue, the touch and close strips and on a single acrylic glass plate. The soft surfaces of the clay cubes fired at $900^{\circ} \mathrm{C}$ were clearly favoured, only a quarter of all colonized clay cubes was of the type 1280 . This preference is obvious in Table 1, although the numbers
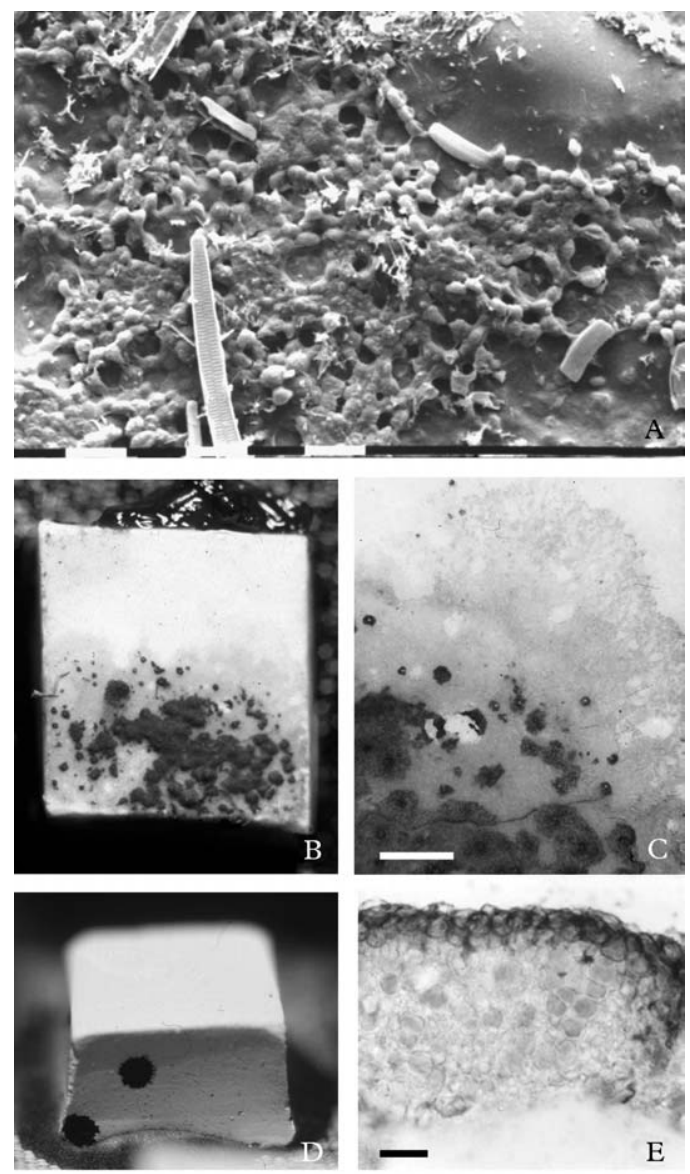

FIG. 3. Colonization of fired clay cubes. A, diatoms (mostly fragments) and a layer of Nostoc sp., on rill surface of a cube type 900, Flüelatal-Karlimatten; $\mathrm{B}$, Verrucaria funckii, on smooth surface of a cube type 1280, Brigels (cube c. $1 \times 1 \mathrm{~cm}$ ); C, detail of B, spreading prothallus; D, small thalli of Staurothele sp., on vertical side of a cube type 900, Flüelatal-Schäferen; $\mathrm{E}$, thallus section of cf. Staurothele (cube type and location as D). Scales: $A=10 \mu \mathrm{m} ; C=1 \mathrm{~mm} ; \mathrm{E}=10 \mu \mathrm{m}$.

were not otherwise statistically analysed. In contrast, preferences concerning the structure of the surface were much less pronounced because many lichen thalli grew on the vertical sides of the cubes (Fig. 3D) and thallus counts on the differently structured horizontal surfaces were not significant. However, it can be concluded that the lichens prefer the unstructured smooth surfaces of the clay cubes. The number of 
TABLE 1. The extent of colonization of clay cubes and rock fragments after 3, 5 and 7 years at the different experimental sites (as \% of all cubes or rock pieces present at each time, and as absolute numbers of colonized cubes)

\begin{tabular}{|c|c|c|c|c|c|c|c|c|c|c|}
\hline & \multicolumn{3}{|c|}{$\%$ of colonized clay cubes } & \multicolumn{3}{|c|}{$\%$ of colonized rock pieces } & \multicolumn{3}{|c|}{ Numbers of colonized replicates of the different substratum types } & \multirow[t]{2}{*}{ Period } \\
\hline & 3 years & 5 years & 7 years & 3 years & 5 years & 7 years & $\begin{array}{l}\text { Cubes } \\
\text { type } 900\end{array}$ & $\begin{array}{c}\text { Cubes } \\
\text { type } 1280\end{array}$ & $\begin{array}{c}\text { Rocks/ } \\
\text { controls }\end{array}$ & \\
\hline Flüelatal-Karlimatten & 0 & $24 \cdot 8$ & - & 0 & $12 \cdot 5$ & - & 25 & 11 & 2 & 1991-96 \\
\hline Flüelatal-Säss & 0 & 0 & - & - & - & - & 0 & 0 & - & 1991-96 \\
\hline Flüelatal-Schäferen & $36 \cdot 0$ & $75 \cdot 9$ & - & 0 & $11 \cdot 8$ & - & 34 & 26 & 2 & 1991-96 \\
\hline Brigels & $4 \cdot 2$ & $19 \cdot 6$ & $38 \cdot 8$ & 0 & 0 & (lost) & 17 & 7 & - & $1991-98$ \\
\hline Eggerberg & $0 \cdot 8$ & $\left(\right.$ n.v. $\left.{ }^{\star}\right)$ & $43 \cdot 8$ & 0 & $\left(\right.$ n.v. $\left.{ }^{\star}\right)$ & 0 & 53 & 3 & 0 & $1991-98$ \\
\hline Total colonized cubes & & & & & & & 129 & 47 & 4 & \\
\hline
\end{tabular}

$\star_{\text {not visited. }}$ 
colonized rock pieces after five years was unexpectedly small, corresponding to less than $10 \%$ of the remaining controls.

\section{Discussion}

\section{The method}

The experimental design proved to be stable enough for studies in alpine streams over several years; the loss of exposed artificial substratum (cubes and plates) was moderate. The use of small substratum units is suitable for SEM analyses of the early stages of lichen development as has been demonstrated previously in studies of juvenile epiphytic lichens (Schuster 1985; Schuster et al. 1985; Ott 1987a, b, c; Scheidegger 1995; Hilmo \& Såstad 2001). Fired clay as a substratum for outdoor experiments was used by Honegger (1993). The most serious problem in the experimental design was the fastening of the clay cubes onto the acrylic glass plates, which should be both firm and reversible. The use of Velcro ${ }^{\circledR}$ fastener proved to be suitable; the removal (collection) of cubes and the replacement were easy, particularly when checking submerged plates. However, some clay cubes fell off the plates, either because of the freezing of water between the nylon strips or weathering of the glue. The latter occurred only on repeatedly dried plates exposed to full sunlight (e.g. Flüelatal-Schäferen). The loss of plates by weathered or abraded cable binders could be minimized by either periodically replacing the binders or by using a higher quality binders.

A disadvantage of the present method is that the anatomical details of thallus development are difficult to observe using light microscopy. For this purpose, a method similar to that described by Sanders \& Lücking (2002) for foliicolous lichens might be employed, whereby thin transparent acrylic platelets (the size of microscope slides) could be exposed, together with the clay cubes, as artificial substrata. The acrylic platelets might then be placed directly under the microscope.

\section{Colonization of the artificial substrata}

The rate of colonization varied from site to site; lichen growth was first visible in the subalpine zone at Brigels, but relatively few cubes were colonized there within seven years. About four months later, small lichen thalli were observed at Flüelatal-Schäferen, growing on a third of the exposed cubes. Most of these cubes were occupied by several thalli. A year later, colonization at Flüelatal-Karlimatten followed; the delay possibly due to the high elevation and harsher climate of the site. However, an effect of altitude was not otherwise evident in this experiment; for example, the rate of colonization at Eggerberg, the lowest site, was not especially high during the first three years. The complete absence of lichen development at Flüelatal-Säss is most probably a consequence of the strong water current and the almost permanent submersion of the artificial substrata. Under these circumstances, the natural lichen vegetation is reduced or sparse.

The period of 3-4 years until the first lichen thalli appeared on the new substrata was similar to the time reported by Degelius (1964), Kristinsson (1974), Ahti (1977) and Armstrong (1981) for terrestrial lichens. However, it must be stressed that the time between the colonization of the substratum by the symbionts and the time of microscopical and macroscopical detection of the lichens may differ considerably. Interestingly, colonization of the clay cubes was faster and more extensive compared with the exposed controls prepared from local rocks. It is not known whether this is due to the physical properties of the clay (e.g., the rather soft, smooth and porous surfaces) or to its chemical composition. Further investigations are now necessary to discover the effect of environmental factors on the rate of lichen colonization and to describe the first stages of thallus development.

I am very grateful to Beat Frey for support for SEM analyses. Thanks are also due to Heinz Läuffer, Christoph Scheidegger, Cornelia Scherrer and Markus 
Schmid for discussions, ideas and help in the experimental design. Jean-Claude Walser, Molly McMullen and François Lutzoni are thanked for reading and improving earlier drafts. William B. Sanders critically commented on the manuscript and made useful suggestions in his review; the final version was written by Urs Groner.

\section{REFERENCES}

Ahti, T. (1977) Lichens of the boreal coniferous zone. In Lichen Ecology (M. R. D. Seaward, ed.): 145-181. London: Academic Press.

Armstrong, R. A. (1981) Field experiments on the dispersal, establishment and colonization of lichens on a slate rock surface. Environmental and Experimental Botany 21: 115-120.

Degelius, G. (1964) Biological studies of the epiphytic vegetation of twigs of Fraxinus excelsior. Acta Horti Gothoburgensis 27: 11-55.

Hilmo, O. \& Såstad, S. M. (2001) Colonization of old-forest lichens in a young and an old boreal Picea abies forest: an experimental approach. Biological Conservation 102: 251-259.

Honegger, R. (1993) A simple outdoor culturing system for the foliose macrolichens Xanthoria parietina (L.) Th. Fr. and Parmelia sulcata Taylor. Botanica Helvetica 103: 223-229.

Jahns, H. M. (1993) Culture experiments with lichens. Plant Systematics and Evolution 187: 145-174.

Jahns, H. M., Mollenhauer, D., Jenninger, M. \& Schönborn, D. (1979) Die Neubesiedlung von Baumrinde durch Flechten I. Natur und Museum 109: 40-51.

Keller, C. \& Scheidegger, C. (1994) Wasserflechten und ihre Standorte im Flüelatal (Schweiz, Kanton Graubünden). Herzogia 10: 99-114.
Kristinsson, H. (1970a) Flechtenbesiedlung auf Surtsey. Schriften des Naturwissenschaftlichen Vereins für Schleswig-Holstein, Sonderband 1970: 29-30.

Kristinsson, H. (1970b) Report on lichenological work on Surtsey and in Iceland. Surtsey Research Progress Report 5: 1 .

Kristinsson, H. (1974) Lichen colonization in Surtsey 1971-1973. Surtsey Research Progress Report 7: 9-16.

Ott, S. (1987a) Differences in the developmental rates of lichens. Annales Botanicae Fennici 24: 385-393.

Ott, S. (1987b) The juvenile development of lichen thalli from vegetative diaspores. Symbiosis 3: 57-74.

Ott, S. (1987c) Sexual reproduction and developmental adaptions in Xanthoria parietina. Nordic Fournal of Botany 7: 219-228.

Sanders, W. B. \& Lücking, R. (2002) Reproductive strategies, relichenization and thallus development observed in situ in leaf-dwelling lichen communities. New Phytologist 155: 425-435.

Scheidegger, C. (1995) Early development of transplanted isidioid soredia of Lobaria pulmonaria in an endangered population. Lichenologist 27: 361-374.

Schuster, G. (1985) Die Jugendentwicklung von Flechten. Ein Indikator für Klimabedingungen und Umweltbelastung. Bibliotheca Lichenologica 20: 1-206.

Schuster, G., Ott, S. \& Jahns, H. M. (1985) Artificial cultures of lichens in the natural environment. Lichenologist 17: 247-253.

Wolseley, P. (1997) Response of epiphytic lichens to fire in tropical forests of Thailand. Bibliotheca Lichenologica 68: 165-176. 